\title{
Increasing the Agility of IT Delivery: Five Types of Bimodal IT Organization
}

\author{
Bettina Horlach \\ University of Hamburg \\ horlach@informatik.uni- \\ hamburg.de
}

\author{
Paul Drews \\ Leuphana University of \\ Lüneburg \\ paul.drews@leuphana.de
}

\author{
Ingrid Schirmer \\ University of Hamburg \\ schirmer@informatik.uni- \\ hamburg.de
}

\author{
Tilo Böhmann \\ University of Hamburg \\ tilo.boehmann@uni- \\ hamburg.de
}

\begin{abstract}
In the age of digital business transformation, enterprises seek to increase their agility and speed of IT delivery. To accomplish this, they change their existing control-driven IT organizational structures and processes and establish separate modes for business-oriented and traditional IT delivery ("bimodal IT"). Though the concept of bimodal IT has been discussed in practice, empirical research regarding the approaches employed to implement bimodal IT is scarce. This paper presents findings from a qualitative-empirical study on the bimodal IT implementation approaches of nine companies. It identifies five different types of bimodal IT in these enterprises and shows that specific mechanisms are applied to enhance the (business) IT alignment in the respective organizational settings of each type. On the basis of similarities and differences among the types, we develop propositions for future research on bimodal IT and derive implications for practice.
\end{abstract}

\section{Introduction}

Digital disruptions, demanding shifts in business models, shorter innovation cycles, and real-time reactions to customer demand, are changing the role of IT. IT services are becoming the primary mode by which many companies-particularly those in the 'new economy' - engage customers and create and capture value. As a result, today's CIOs must find a balance between establishing new revenue streams and improving customer experience, on one hand, and the need to 'keep the lights on,' on the other. Companies of the 'old economy' often struggle with this balance because of their rigid and process-driven IT organization. To cure this lack of flexibility in companies' IT, advisory firms, such as Gartner or McKinsey, propose to establish two modes of IT delivery ("bimodal IT" or "two-speed IT") [1-3]. Mode 1 encompasses the operation of the company's core systems, including sequential and long development cycles and process-driven and control- driven IT infrastructure and organization. Mode 2 is responsible for digital innovation [1]. This second mode reacts to rapidly changing customer needs in fast, customer-facing and business-oriented IT organizations. Bimodal IT, thus, seeks to narrow the gap between IT delivery and business needs, a major goal that has been pursued by business executives and IT management for more than 30 years $[4,5]$.

While bimodal IT has received significant attention from practitioners, academic research is still in its nascent phase. Only two academic research papers address this concept $[6,7]$. Thus, it is unclear how bimodal IT is implemented in practice and to what extent alignment between business and IT is fostered through the application of bimodal IT.

This paper, accordingly, seeks to answer the following research questions:

1. How is bimodal IT realized in practice?

2. How is business IT alignment affected by bimodal IT, and what approaches do companies use to enable alignment within IT and in relation to business in the bimodal IT environment?

The remainder of the paper is structured as follows. In the following section, we briefly describe bimodal IT and business IT alignment as the conceptual foundations for our analysis. Thereafter, we outline the methodology of our analysis and summarize the main results. Finally, we propose future research opportunities.

\section{Related Research: Business IT Alignment and Bimodal IT}

Business IT alignment is an extensively studied concept in IS research [8]. It is understood as "the optimized synchronization between dynamic business objectives/processes and respective technological services provided by IT" [9]. Previous research on business IT alignment has focused primarily at the company-wide strategic level $[10,11]$. However, to successfully transfer business or IT strategies into daily business operations, constant interaction 
between the strategic and the operational levels is inevitable $[8,12,13]$. This, in turn, requires alignment across several organizational levels [8]. First, alignment is required at the individual cognitive level. This level forms the basis for an understanding of others' perspectives on values, beliefs, mental models, expectations, and assumptions [14], which is necessary to foster shared understanding and domain knowledge [15] based on shared cognition [14]. Second, alignment is essential at the group level such as in project settings [16]. This is mainly required to ensure that a project's outcomes fit the IT strategy [ibid.]. Finally, alignment among groups at different department and organizational levels, either within IT or between development and operations [13] or business and IT departments must be enhanced through cross-departmental interactions. This is necessary to foster informational flows, shared knowledge and trust-building throughout departments [17].

Bimodal IT is defined by Gartner as "the practice of managing two separate, coherent modes of IT delivery, one focused on stability and the other on agility. Mode 1 is traditional and sequential, emphasizing safety and accuracy. Mode 2 is exploratory and nonlinear, emphasizing agility and speed" [1]. Mode 1 involves long-term plans, goals, and development applying the waterfall methodology [18]. Information systems associated with this mode are mission- or business-critical systems that are always running [19]. For these "systems of record," business involvement in the application lifecycle is usually limited [8]. Furthermore, silos for development, testing and operations are common [18]. With highly specialized metrics to ensure stability, efficiency, safety, and accuracy [18], mode 1 is responsible for minimizing operational risks while driving service industrialization [20]. Mode 2, in contrast, focuses on the agility and speed of IT delivery to assist the business driving innovation to meet rapidly changing market requirements [18]. Using agile methodologies and new types of technologies, such as cloud-based environments [19] and microservices - simple services designed to, for example, retrieve customer information [20]—-mode 2 enables the rapid development, testing, and operation of market-facing systems and services to quickly respond to market feedback [20]. These "systems of engagement" [19] are usually noncritical systems with low risk and low cost, and they are developed in an environment in which IT acts as a start-up within the enterprise, with lightweight governance models [20] and a DevOps culture [18].

Business IT alignment is affected by bimodal IT in two ways. First, unlike established alignment frameworks (e.g. [10, 15]), bimodal IT implies the existence of two IT organizations instead of a single IT. Thus, bimodal IT leads to new alignment dimensions [7]. On one hand, dependencies among systems and operations ("Bimodal IT Alignment") produce a certain degree of alignment among IT modes. On the other, alignment between business and both IT delivery modes is also required ("Bimodal Business IT Alignment"). In the case of decentralizing parts of agile IT towards former nonIT business units, alignment with the respective business units becomes necessary ("Business Digital IT Alignment"). Second, the established alignment frameworks perceive business and IT as two separate units. As IT is becoming a major factor in value creation in the digital age, a shift towards the convergence of business and IT through, for example, merging business and IT strategy in a "Digital Business Strategy" [21] or "Digital Transformation Strategy" [22] is proposed instead. Bimodal IT is assumed to be a concept for achieving a closer integration of business and IT.

\section{Research Methodology}

Since bimodal IT has rarely been a subject of scientific research, we seek to approach this topic by applying the phenomenon-based research approach according to von Krogh et al. [23]. According to this approach, research on a phenomenon has three stages of development: embryonic, growth, and mature. Within each stage, five research strategies are identified: "distinguish," "explore," “design," "theorize," and "synthesize." For bimodal IT, research occurs in the embryonic stage, and we use the explore strategy to analyze the implementation of bimodal IT and its effect on alignment. Therefore, we conducted a qualitative-empirical study based on nine interviews with IT management representatives from different service-related industries. Each interviewee was responsible for the bimodal IT implementation of the respective organization. The companies differed in their status quos regarding the implementation of bimodal IT: While a few were in the early stages or considering or planning the introduction of dual IT modes, others had already established bimodal structures and processes. Detailed information about the interviewees is presented in Table 1.

The initial set of interviewees was based on the authors' personal contacts. Then, a snowball sampling strategy [24] was conducted. For the interviews, we used semi-structured interview guidelines with open questions [25], which enabled the interview partners to speak freely about their individual experiences with the implementation of 
bimodal IT and their perceptions of the effects of bimodal IT on alignment. To analyze the effects of bimodal IT at the different alignment levels (see section 2), the guideline was structured based on the alignment dimensions of business IT alignment and IT alignment within and between IT delivery modes.

Table 1. Interview overview

\begin{tabular}{|c|l|l|l|l|}
\hline ID & \multicolumn{1}{|c|}{ Position } & \multicolumn{1}{|c|}{$\begin{array}{c}\text { Stage of } \\
\text { Implementation }\end{array}$} & $\begin{array}{c}\text { Company } \\
\text { Size }\end{array}$ & Industry \\
\hline 1 & $\begin{array}{l}\text { Staff Unit for } \\
\text { Head of IT }\end{array}$ & Planning & $>2000$ & IT Services \\
\hline 2 & Head of IT & Planning & $<50$ & Banking \\
\hline 3 & $\begin{array}{l}\text { Project Manager } \\
\text {,Agile Transformation" }\end{array}$ & Implementing & $>100.000$ & Banking \\
\hline 4 & $\begin{array}{l}\text { Staff Unit for } \\
\text { Head of IT }\end{array}$ & Implementing & $>1000$ & Insurance \\
\hline 5 & $\begin{array}{l}\text { Staff Unit for } \\
\text { Head of IT }\end{array}$ & Implementing & $>2500$ & Insurance \\
\hline 6 & $\begin{array}{l}\text { Head of Department } \\
\text { "Change the Bank" }\end{array}$ & Implementing & $>2500$ & Banking \\
\hline 7 & $\begin{array}{l}\text { Head of Department } \\
\text { "Platform Services" }\end{array}$ & Implementing & $<10.000$ & E-Commerce \\
\hline 8 & Senior Consultant & Planning & $>500$ & IT Consulting \\
\hline 9 & $\begin{array}{l}\text { Staff Unit for } \\
\text { Head of IT }\end{array}$ & Implementing & $>10.000$ & Banking \\
\hline
\end{tabular}

Between December 2015 and April 2016, we conducted two on-site and seven telephone interviews, each approximately about 60 minutes in length. All interviews were digitally recorded for traceability and were completely transcribed for further analysis. To conduct the analysis, we followed an iterative process of inductive and deductive data coding [26], using the ATLAS.ti tool for support. Based on both the interview guidelines and previous work on business IT alignment [8, 9], one author identified bimodal IT characteristics and searched for evidence of business IT alignment in relation to bimodal IT using open coding [27]. Other bimodal IT characteristics, such as the category sourcing (see Table 2), were generated from the bottom up. In sum, 733 codes were used. The codes were then merged into categories like sourcing. Finally, we identified and compiled detailed descriptions of the bimodal IT approaches. Throughout this process, the findings were discussed among the authors and iteratively refined. This process of data gathering and data analysis will be continued in the future to address some of the open research questions raised at the end of this article.

\section{Results: Five Types of Bimodal IT}

This section reflects the results of the interviews, on the basis of which we identified five types of bimodal IT (see Table 2). Thereafter, we will describe the implementation approach and the alignment mechanisms for each type. We will show how agile IT is embedded in the IT organization (location) and highlight the role of outsourcing. We will further highlight the reach of agile IT in order to indicate which parts of the IT value network operate in this mode, as well as how agile IT is managed and controlled. Finally, we will show how the alignments between traditional and agile IT and between (agile) IT and business are achieved. The order in which we describe these five types is based on the extent and degree of changes a traditional IT organization needs to make in order to implement the respective bimodal IT type. We begin with the least intrusive type.

\subsection{Traditional IT with bimodal development processes}

The first type of bimodal IT we identified in one organization is characterized by traditional IT, with bimodality limited to the development process, which uses both agile and traditional process-driven waterfall development methodologies. Other phases, such as planning, testing and operations, continue to follow the traditional waterfall approach, with a high level of control in each step. This bimodal development approach applies to the development of new and changes to existing 'systems of records,' as well as to the development of customer-centric information systems, such as mobile applications.

Because the development process is embedded in the waterfall process, agility is strongly inhibited when developing customer-centric applications. This problem occurs most frequently when a developed application leads to modifications of or extensions to legacy systems, which usually have releases only once or twice a year. In such an event, a complex change management process is initiated. Thus, the 'systems of engagement' can only be released in the same cycles as changes to the 'systems of record.'

Bimodal IT alignment for this type is usually enabled through projects and through the interaction among people within each project. For example, mobile developers enable knowledge sharing with operations during the handover process. Since development and operations are not co-located in the interviewed company, knowledge sharing is achieved through formal meetings, not continuous exchange. There is no formal mechanism for interaction between projects; instead, this occurs implicitly.

Business (i.e. the customer) and IT align primarily through interdisciplinary steering committees for planning and governance. These involve boards for traditional project portfolio management and boards for making decisions on overall standards and 
Table 2. Overview of the characteristics of identified bimodal IT types

\begin{tabular}{|c|c|c|c|c|c|c|}
\hline & Traditional IT with & & Bimodal & sourcing IT & & \\
\hline & $\begin{array}{l}\text { bimodal development } \\
\text { processes }\end{array}$ & $\begin{array}{l}\text { Traditional IT with } \\
\text { agile IT outsourcing }\end{array}$ & $\begin{array}{l}\text { Bimodal sourcing IT } \\
\text { (outsourcing) }\end{array}$ & $\begin{array}{c}\text { Bimodal sourcing IT } \\
\text { (project) }\end{array}$ & Bimodal IT & Agile IT \\
\hline \begin{tabular}{|l|} 
Location of \\
agile IT
\end{tabular} & $\begin{array}{l}\text { Agile development } \\
\text { process within waterfall } \\
\text { project }\end{array}$ & $\begin{array}{l}\text { Agile project out-sourced } \\
\text { to third party provider(s) } \\
\text { or subsidiaries }\end{array}$ & $\begin{array}{l}\text { Agile project outsourced to } \\
\text { third party provider(s) or } \\
\text { subsidiaries }\end{array}$ & $\begin{array}{l}\text { - Agile internal project } \\
\text { - Project members except } \\
\text { project manager sourced } \\
\text { from third party provi- } \\
\text { der(s) or subsidiaries }\end{array}$ & $\begin{array}{l}\text { Separate agile IT } \\
\text { organization with multiple } \\
\text { agile interdisciplinary } \\
\text { DevOps teams }\end{array}$ & $\begin{array}{l}\text { Unimodal agile IT } \\
\text { organization with multiple } \\
\text { autonomous agile } \\
\text { interdisciplinary DevOps } \\
\text { teams }\end{array}$ \\
\hline $\begin{array}{l}\text { Reach of } \\
\text { agile IT }\end{array}$ & Development & Development & $\begin{array}{l}\text { Development } \\
\text { Operations }\end{array}$ & $\begin{array}{l}\text { Development } \\
\text { Operations }\end{array}$ & $\begin{array}{l}\text { Development } \\
\text { Operations } \\
\text { Business (Digital Business } \\
\text { Units) }\end{array}$ & $\begin{array}{l}\text { Development } \\
\text { Operations } \\
\text { Business (Planning, } \\
\text { Budget, Digital Business } \\
\text { Units) }\end{array}$ \\
\hline \begin{tabular}{|c|} 
Role of \\
outsourcing \\
of agile IT
\end{tabular} & N.A. & $\begin{array}{l}\text { Use outsourcing to } \\
\text { become more agile }\end{array}$ & $\begin{array}{l}\text { Use outsourcing to become } \\
\text { more agile }\end{array}$ & $\begin{array}{l}\text { Use outsourcing to become } \\
\text { more agile }\end{array}$ & N.A. & N.A. \\
\hline \begin{tabular}{|c|} 
Control of \\
agile IT
\end{tabular} & $\begin{array}{l}\text { Managed by traditional } \\
\text { IT project management }\end{array}$ & \begin{tabular}{|l|} 
Steered by traditional IT \\
as client via con-tracts \\
$\&$ agreements \\
- Managed by internal \\
project steering \\
organization
\end{tabular} & $\begin{array}{l}\text { - Steered by sourcing IT } \\
\text { as client via contracts } \\
\text { \& agreements } \\
\text { - Managed in developm. } \\
\text { via formal meetings } \\
\text { - Managed in operations } \\
\text { via support structures }\end{array}$ & $\begin{array}{l}\text { - Steered by internal agile } \\
\text { project management } \\
\text { - Project organization } \\
\text { steered by project steering } \\
\text { boards, IT controlling } \\
\text { department \& project } \\
\text { coordinators }\end{array}$ & $\begin{array}{l}\text { - Product owner technical } \\
\text { lead for agile team } \\
\text { - Steered by additional } \\
\text { management regarding } \\
\text { disciplinary \& technical } \\
\text { leadership } \\
\text { - Program management via } \\
\text { Scaled Agile Framework }\end{array}$ & $\begin{array}{l}\text { - Self-control by autono- } \\
\text { mous teams (Technical } \\
\text { leadership \& decision } \\
\text { power in team) } \\
\text { - Community control via } \\
\text { chapters \& guilds } \\
\text { - Code of conduct per } \\
\text { team \& between teams }\end{array}$ \\
\hline \begin{tabular}{|c|} 
Alignment \\
betwen \\
agile \& \\
traditional \\
IT
\end{tabular} & $\begin{array}{l}\text { Interaction in project (e.g. } \\
\text { knowledge sharing during } \\
\text { handover process) }\end{array}$ & $\begin{array}{l}\text { - Project management } \\
\text { - Co-location of project } \\
\text { team within company } \\
\text { - Project portfolio }\end{array}$ & Not specified (external) & $\begin{array}{l}\text { - Project coordinator } \\
\text { - IT controlling departm. } \\
\text { - Co-location of project } \\
\text { team within company } \\
\text { - Bimodal skill develop- } \\
\text { ment for project manager } \\
\text { - Project portfolio mgmt. }\end{array}$ & $\begin{array}{l}\text { - Bimodal skill develop- } \\
\text { ment for staff } \\
\text { - Interaction CDO \& CIO } \\
\text { - Interaction in change } \\
\text { management process }\end{array}$ & Not needed (only agile IT) \\
\hline $\begin{array}{c}\text { Alignment } \\
\text { between } \\
\text { (agile) IT \& } \\
\text { business }\end{array}$ & $\begin{array}{l}\text { - Business project co- } \\
\text { manager } \\
\text { - Steering committee } \\
\text { for planning \& gover- } \\
\text { nance }\end{array}$ & $\begin{array}{l}\text { - Requirements } \\
\text { engineering } \\
\text { - Steering committee } \\
\text { for planning \& gover- } \\
\text { nance }\end{array}$ & $\begin{array}{l}\text { - Requirements } \\
\text { engineering } \\
\text { - Steering committee for } \\
\text { planning \& governance }\end{array}$ & $\begin{array}{l}\text { - Business project co- } \\
\text { manager } \\
\text { - Steering committee for } \\
\text { planning \& governance } \\
\text { - Business Architect as } \\
\text { project coordinator on } \\
\text { business side }\end{array}$ & $\begin{array}{l}\text { - Product Owner part of } \\
\text { agile team } \\
\text { - Digital business units } \\
\text { - IT-Business Relationship } \\
\text { Management function } \\
\text { - Steering committee for } \\
\text { planning \& governance }\end{array}$ & $\begin{array}{l}\text { - Product Owner part of } \\
\text { agile team } \\
\text { - Digital business units } \\
\text { - Common planning, bud- } \\
\text { geting \& governance } \\
\text { steering committees } \\
\text { - Lean Governance (e.g. } \\
\text { Objective Key Results) }\end{array}$ \\
\hline
\end{tabular}

architectural aspects, such as programming language and applied technology. At the operational level, business IT alignment mainly takes place between the project manager and the rest of the project team.

\subsection{Traditional IT with agile IT outsourcing}

A second mode of bimodal IT we encountered in two organizations focuses on the traditional capabilities within the IT organization. The agile IT is achieved via third party providers or subsidiaries. This results in a partly outsourced IT organization with a traditionally organized ('slow') internal IT and an agile ('fast') external IT.

This type has several commonalities with the first type, such as its functional internal traditional IT organization and its waterfall-driven IT delivery with dedicated and traditionally rigid processes concerning planning, operations, and project governance. However, companies of this type have realized that agile development cannot fulfill business needs on its own. This is substantiated by the fact that business units established a parallel IT organization within their units with the help of external providers to solve their problems without involvement of the main IT department due to internal IT's "many barriers, acceptance, security restrictions, relatively rigid processes and resulting long lifecycle," as one interviewee stated. To prevent this emergence of shadow IT, this type of IT organization might draw upon one or multiple third party providers or subsidiaries to establish an agile IT mode externally which is internally steered by traditional IT.

The outsourcing of agile IT is primarily intended to overcome the "processual abyss" and slow speed of internal IT. Furthermore, such initiatives can build trust from business that "IT can deliver a solution which still satisfies their needs," as an interviewee pointed out. Since the companies are operating in rapidly changing areas, time to market is further envisioned, requiring short-run IT capabilities that internal IT cannot currently provide.

To enable internal alignment at a project level, an internal project-steering organization is created that consists of the application's business owner and the central requirements management function of IT. External project alignment is established mainly through contracts or agreements. However, alignment can also be achieved by seating external staff inhouse to foster knowledge sharing among internal staff due to informal communication.

On the strategic level, there is a clear distinction between business and IT of the duties in this type. The business units are perceived as customers of the 
IT, resulting in individual and business-exclusive product portfolio planning and budgeting. The responsibilities of the IT department lie in condensing the resulting product portfolios into a single project portfolio. Additionally, a dedicated IT department has the task of ensuring the compliance of individual product portfolios submitted by each business unit with formal and legal requirements. During this process, the people in charge of the product portfolios from business and the IT portfolio department have to collaborate tightly. Over the course of the project, interaction between business and IT occurs within formal steering committees, which make decisions regarding, for example, scope. This applies to both waterfall and agile projects.

\subsection{Bimodal sourcing IT}

Outsourcing one IT delivery mode while keeping the other in-house is not the only prominent approach for enabling agility in traditional IT; outsourcing both modes is also popular. As one interviewee stated, the flexibility of integrating the skills of external partners is one argument for using outsourcing services for both traditional and agile IT. Another interviewee went a step further, declaring that outsourcing is critical for agility as "our hands are tied since we do not develop the IT ourselves." However, internal supervision is still necessary to fulfill external requirements, since "financial service providers have also to provide very detailed plans to the auditors."

When outsourcing both IT delivery modes, two different types of corporate IT organizations that shape the role of internal IT can be distinguished:

(1) A client-supplier relationship between corporate IT and the outsourcing partner

(2) Internal IT project organization, with corporate IT as a project manager and an outsourcing partner for a project team

Each type has been identified in one organization.

The first setting resembles the traditional customer-supplier relationship in a bimodal manner, with corporate IT being the client and one or multiple outsourcing partners or subsidiaries for the IT delivery modes. In this type, the corporate IT commissions the supplier(s) for one of the modes and sets the requirements for the specific service. The delivery lies solely in the hands of the outsourcing partner, such that internal IT has little operational involvement. Internal IT also acts as the governance instance during the development phase to monitor progress through regular meetings with the partner.

The relationship with the corporate business is a traditional client-supplier structure. This implies a similar approach to the planning and the governance as used in the bimodal IT approaches described above. Governance mechanisms like steering boards are used, as are waterfall-like planning processes. Alternatively, planning is conducted and steered by dedicated business and IT departments.

The second form of bimodal outsourcing focuses on a lower degree of outsourcing. In this setting, both agile and traditional projects are steered internally, while the resources for development, testing, and operations are sourced from outsourcing providers. Thus, the internal bimodality lies in the bimodal skills of the project managers.

In this type, the project manager is in charge of the project methodology. To ensure an appropriate decision, project managers need to be able to master both agile and traditional methodologies. Thus, project managers need to be equipped with vast methodological skill sets through systematic training. Since such training is usually managed by the human resources department, all IT and business employees can apply for training in agile. However, external staff are expected to already have the requisite skills.

Alignment among project managers is fostered in two ways. The first is via the project coordinator, who is responsible for governance and determines whether the applied approach is applicable for developing the solution, particularly at the beginning of the project. This role acts as a 'hub' through which bilateral exchanges with all project managers occur; however, no direct exchange among the managers is facilitated. The same applies to the ongoing interaction with the central IT controlling department, which has the task of ensuring that all projects fulfill formal requirements, such as compliance and other policies. Direct interaction among project managers is ensured by locally centralizing all people in a department with fixed workplaces.

Alignment between business and IT is enhanced mainly by establishing steering boards together with the outsourcing partner to govern one or multiple projects. At the project level, alignment is fostered by appointing one technical IT and one business project manager per project. Finally, a business program manager is appointed as a business counterpart to the IT project coordinator. This business program manager continuously interacts with the business units involved in the projects and, thus, acts as a 'hub' for the business side.

\subsection{Bimodal IT}

Two investigated organizations decided to implement bimodal IT in-house, without giving outsourcing providers a major role. This type of bimodal IT characterizes the separation of the two IT 
delivery modes regarding structures and processes. The separation can culminate in separating executive leadership, with a Chief Digital Officer (CDO) being responsible for the agile IT and the CIO being responsible for the traditional IT organization.

Though it also targets "time to market, creativity and collaboration with customer proximity fostering innovation", internal agile IT mainly ensures "higher agility, flexibility and reactivity towards customers" with internal IT for the firms. Knowledge about the organization of the agile IT is seen as "intellectual property" and is considered a valuable asset. Outsourcing is not an option for these companies. As one interviewee puts it: "outsourced competencies are lost after 3-5 years. Then, it takes decades to build this know-how within the organization again."

Regarding the organizational structure, a separate agile IT organization and agile processes are currently being set up in these companies. While the traditional IT organization is still functionally structured and managed, new approaches for structuring agile IT, such as the concept of small (5 to 10 people) agile interdisciplinary business and IT teams, are being piloted. These are divisional teams, formed based on features as fractures of a complex service instead of the grouping of functions. The core method typically applied within these agile teams is scrum. Thus, the teams usually involve a product owner from business as well as a development team and a scrum master. The application of scrum in this context has several differences from the original scrum concept. First, the product owner is an active member of the team in all stages from planning to deployment, locally sitting together with the team instead of guiding the requirements engineering from the outside. Second, the sprint duration can be adapted to the requirements in terms of complexity and effort. However, the management structures for the agile teams are steered traditionally, with a personal union of disciplinary and technological leadership for each team. For the future, flat hierarchies within agile IT are planned instead.

Working in agile IT requires a different skillset that is sometimes not sufficiently provided by internal staff members. Thus, insourcing is a prominent approach in this type. To staff the agile IT organization, the companies apply a plethora of sourcing mechanisms. For internal talent management, events like hackathons within the traditional IT department are organized. Further actions include reviews of skill sets and training in agile methodologies as well as the possibility for job rotation. These are conducted not only within the IT organization, but via the rotation of staff with certain skill sets from different business units. External talent management is mainly executed by insourcing from outsourcing partners. The degree of insourcing varies within departments and between companies. Many solely insource staff with certain skills and a t-shaped character. Such an approach implies that the talent has expertise in one context (e.g. cloud operations) and fundamental knowledge in multiple other domains. In certain new digital areas, such as data science and UX design, the focus is more on seeking specialists. Instead of pursuing individual staffing, agile IT organizations also increasingly maintain partnerships with one or several partners with digital expertise, such as specialized agile start-ups. To insource this talent, these companies are sometimes acquired by the larger organization.

To separate traditional and agile IT at a process level, agile teams include sourced operations staff in the team structure and use cloud solutions for testing and operations environments, following the DevOps methodology. This enables agile IT to operate separately from traditional IT and further fosters intra-team alignment between development and operations. Since independency is also applied to other agile teams, the architectural concept of microservices is increasingly used in agile teams with small independent services, which can only be accessed via a standardized API. These services can then be composed into complex IT business services. However, in practice, dependencies between the two IT delivery modes still exist (e.g., through the use of data and functionalities from traditional IT legacy systems in agile IT services).

Agile IT has the role of narrowing the distance to the business organization so that IT becomes a partner instead of a service provider. While this is facilitated by the close proximity of the business product owner at the team level, similar approaches are needed at the program and strategy levels as well to improve the alignment. Frameworks like the Scaled Agile Framework (SAFe) [28] for scaling agility in a process-driven way at strategic, program, and project levels are increasingly used to approach this challenge. The SAFe framework implies an ongoing and tight partnership between IT and business throughout the delivery process from planning to deployment. For the planning phase, one organization currently argues for the use of such methodologies as design thinking or business games to deepen the business IT relationship to promote shared idea generation regarding new potential products. Finally, a step towards business IT partnership is to locate agile teams inside the business location, such that both ideally sit together in one place. Both organizations plan or have already established digital business units, which are dedicated 
units consisting of both business and IT staff for developing digital services. This proximity maximizes the bilateral exchange of knowledge and information and enhances shared domain knowledge.

Currently, traditional governance approaches, such as steering boards and jour fixes, are still the most common pathways of interaction between business and IT. Furthermore, a central business relationship management function for both agile and traditional IT enhances the IT business relationship by 'listening' into current strategic business initiatives and filtering the required IT skills to realize respective initiatives. This role also serves as central demand and IT project portfolio manager and is responsible for governance with respect to formal requirements within the studied organization.

\subsection{Agile IT}

The last type of bimodal IT, which we identified in two organizations, is characterized by an internal, unimodal, agile IT organization that seeks to drive business agility and time-to-market via a rapidly responding IT organization. Internally, this organizational setup was favored by the interviewees for driving efficiency and performance because it "prevents whispers down the lane" by "reducing the number of parties in the backseat drive." Communication overhead and long project durations are, thus, avoided, and agility is, in turn, enabled.

To realize this agility within IT at the lowest level, autonomous agile interdisciplinary teams, which have long-term responsibility for a single feature of a service, are used. Team members are responsible for the entirety of the IT delivery process, from planning to operations, as well as for quality assurance; thus, they follow the DevOps methodology. These teams have democratic structures resulting in autonomic decisions based on discussions among the team members, typically regarding how to develop the solution and team management. Unlike the agile teams in the former type, these teams act as self-organizing units. They not only have responsibility for the applied method and sequence of task completion, but are also responsible for team composition, decision structures and the overall team mission. Functional leadership for these teams is provided by the product owner, who is responsible for prioritizing the work of the team and is also a member of the team. Due to the team's autonomy, there is no disciplinary leadership. Instead, each employee has a dedicated supervisor who is responsible for the individual personnel development. This supervisor works in the central human resources department.
Every autonomous team belongs to a divisional department. While these departments are led by dedicated managers, these managers exist solely in a coaching capacity for the individual teams. Coaching includes, for instance, acting as a mediator in case of conflicts or enforcing decision-making if a team gets stuck. Furthermore, the managers can advise teams to use specialized coaches, such as agile coaches, for methodology consulting and decision support, or specialized project managers for managing projects consisting of multiple teams; these additional coaches are provided by the organization. Finally, the managers are responsible for setting up the department's annual goals, which are fulfilled at the beginning of the year based on corporate goals. For this purpose, one company follows Intel's concept of "Objective Key Results" (OKR) [29] which focuses on qualitative objectives for whose fulfillment every employee autonomously defines measurable key results. Both objectives and key results are accessible to all members of the organization.

To foster alignment within the entire IT organization, while simultaneously scaling agility, team-based frameworks, such as Spotify's model [30], are increasingly used in this type. According to this model, companies not only create feature-based autonomous teams, which are called 'squads,' but also combine them into departments, known as 'tribes', based on products. Shared knowledge and understanding among autonomous teams is enhanced throughout the organization by establishing semiformal 'chapters' of employees with similar professional functions and 'guilds' of larger communities of interests, which allow employees to discuss knowledge and practice. While chapters usually reside in one tribe, guilds enable organization-wide communication.

Alignment with business is enabled not only by including the business product owner as a team member, but also by establishing digital business units by integrating the team inside the business unit using the developed digital product. At the executive level, business is involved in the product portfolio management process, as well as in meetings for budgeting new products. Unlike in the types described above, in this type, budgeting negotiations are product-driven instead of project-driven.

Governance and compliance at the team level is kept simple through OKR and support via monitoring tools. Currently, there is no monitoring for team effectiveness; instead, teams follow codes of conduct. The way in which the teams reach their solutions is also not monitored. This applies to the organizational level, as well. Instead of process monitoring and 
optimization, the IT organization governs the success of the business models.

\subsection{Cross-type alignment analysis}

Comparing the alignment approaches of the five bimodal IT types shows that each type uses distinct mechanisms based on the respective setting (see Table 2). However, a comparison of all five types also shows some similarities, especially regarding business IT alignment at all organizational alignment levels [8]. At the individual level, cognitive business IT alignment is trained primarily on the job for all types. However, given the increasing extent of bimodality within the organizations, dedicated business skill development for IT staff needs to be a core focus. 'T-shaped' people have not only IT skills, but also business knowledge gained during training or on the job. IT training for business staff is not common, but is mainly achieved through job rotation. At the personal and team levels, business IT alignment further depends on the extent of involvement of the product owner in the team setting. This role transports the overall strategy into IT by transforming business goals into product requirements. All types incorporate business product owners within their agile projects. The function of this role differs among the types. While, in the first four types, the product owner functions merely as outside requirements engineering, in the 'Bimodal IT' and 'Agile IT' types, this individual plays an integral part of the team. At the program level, traditional formal business IT alignment mechanisms, such as steering boards and process controls, still dominate in all types. These include highly formalized planning processes, such as portfolio management and requirement engineering. Only small steps towards agility have been taken by bimodal IT, mainly in the 'Agile IT' type, which has introduced Objective Key Results and lean management and governance. At the organizational level, a larger part of agile IT leads to a shift from a process-driven functional towards a product-based divisional IT organization. This culminates in interlinking, dedicated, autonomous agile teams with corresponding business teams as business digital units. A higher level of agile IT requires more comprehensive changes to the operational business.

Although a formal separation between traditional and agile IT is envisioned in bimodal IT, alignment between the modes is still necessary for establishing a shared understanding. For this purpose, well-known alignment mechanisms are widely applied at all organizational levels. At the individual level, the individual employee trains in bimodality on the job via working in projects and engaging in related interactions for most of the types. In addition, dedicated bimodal skill development, such as training in agile methodologies, is available for staff members. At the team and department levels, traditional formal mechanisms, such as common project steering boards, IT controlling functions, and formal project portfolio management, are still dominant in all types for aligning the IT delivery modes. Agile IT also enables direct bimodal IT interaction within change management processes to modify legacy systems based on requirements. For 'Agile IT' and 'Bimodal IT', the DevOps methodology of incorporating existing operations staff into agile teams is further introduced to align traditional and agile IT. For the types using outsourcing, alignment is facilitated mainly by formal mechanisms, such as contracts and agreements, as well as by steering meetings with the outsourcing partner. At the organizational level, alignment currently focuses on shared understandings based on ongoing interactions between the $\mathrm{CIO}$ and the $\mathrm{CDO}$.

\section{Discussion and Practical Implications}

Our research was motivated by the lack of empirical research on bimodal IT implementation and alignment mechanisms. By conducting an exploratory study with a small set of service-related organizations, we identified five types of bimodal IT (see Figure 1) that are adopted in practice, each of which has distinct characteristics regarding bimodality and, in particular, regarding the location and reach of the agile IT organization (see Table 2). With regard to the second question, "How is alignment affected by bimodal IT?" our study confirms that the heterogenic nature of IT in bimodal IT leads to three new forms of alignment dimensions: 'Bimodal Business IT Alignment,' 'Bimodal IT Alignment,' and 'Business Digital IT Alignment' [7]. However, our results further enrich the three dimensions by observing different alignment mechanisms among the identified bimodal IT types. While 'Bimodal Business IT Alignment' is evident in all five types, for the majority of types, alignment either focuses on traditional, sourcing IT or takes place solely between business and agile IT. 'Bimodal Business IT Alignment' between both delivery modes [7] is evident only in 'Bimodal IT', in which both modes directly interact with business. 'Bimodal IT Alignment' is also present in all types except 'Agile IT.' However, our study shows that, due to the outsourcing of one or both modes in half of the types, this alignment dimension needs to be extended via an external dimension to incorporate the fit between the 

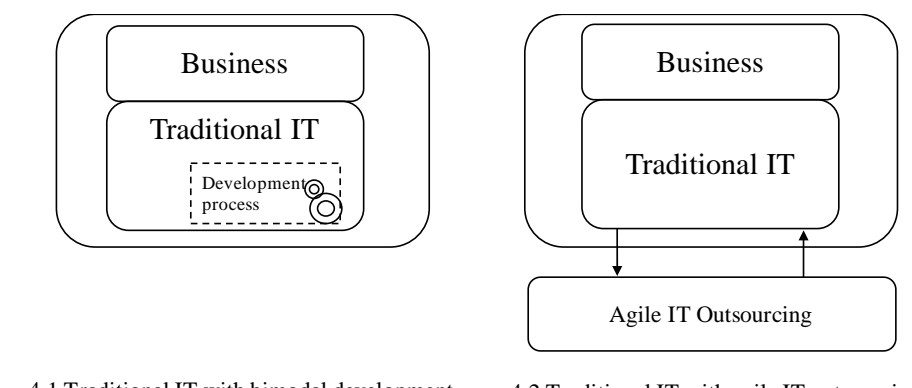

4.1 Traditional IT with bimodal development

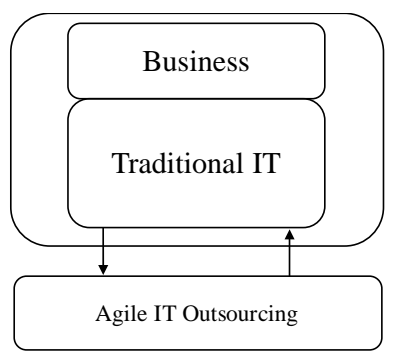

4.2 Traditional IT with agile IT outsourcing

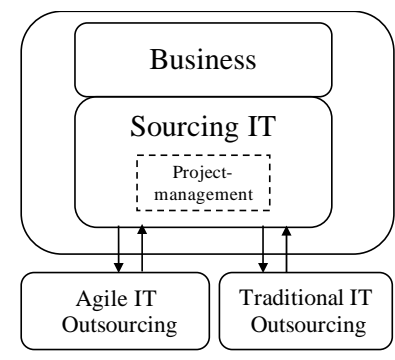

4.3 Bimodal sourcing IT with or without project management

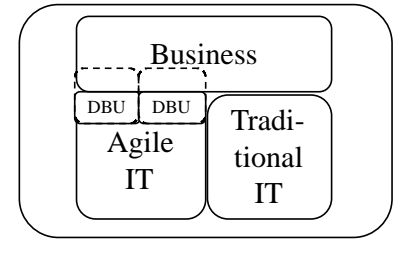

4.4 Bimodal IT with or without digital business units

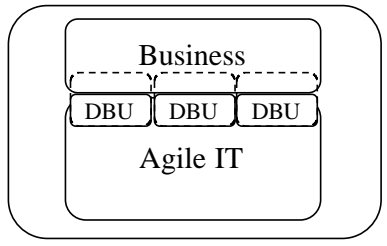

4.5 Agile IT with or without digital business units

Figure 1. Identified bimodal IT types

internal IT organization and the corresponding outsourcing partner(s). Regarding 'Business Digital IT Alignment,' no heterogeneity is identified.

Previous literature on alignment advocates optimizing the fit between business and IT at the strategic and operational levels (e.g. [4, 10, 15]). While established alignment frameworks, such as [10], address the fit between a single, homogeneous, traditional IT and the business side, bimodal IT implies further types of fit between new and multiple forms of IT delivery, all with differing expected outcomes and visions. Moreover, agile IT aims to converge with business. In this regard, our study supports Bharadwaj et al. [21] and Matt et al. [22], who advocate the closer integration of business and IT, considering the differing needs of the digital age. By highlighting useful existing organizational approaches for business IT convergence, such as 'digital business units' and 'Objective Key Results,' based on the findings, we provide the missing link in the strategic operationalization of these concepts.

For practitioners, this study is relevant because the results highlight the multi-faceted nature of bimodal IT. Driven by the desired outcome and the desired speed of this outcome, as two contingency factors influencing the organizational arrangements, executives must choose a specific bimodal IT strategy. The bimodal IT strategy is inextricably linked to the sourcing strategy, since a move towards agile IT creates new requirements for sourcing arrangements. Alternatively, given a lack of internal capabilities, it can be a solution for realizing agile IT.

With respect to alignment, new solutions are needed to enable a new business IT alignment by integrating business and IT more closely. In terms of governance, ways to loosely couple bimodal governance approaches to fully enable speed in agile IT, while still achieving high control in traditional IT, must be developed. In sum, companies need to be very clear about whether bimodal IT is their desired target state or a transitory state for them. Some practitioners are defining bimodal IT as a targeted state, while others see bimodal IT as a step towards achieving full agility in their IT organization.

Examining our results critically, we conclude that the 'Agile IT' type is exceptional in our study. If a strict definition of bimodal IT is applied, 'Agile IT' would not be bimodal IT, since it is characterized by internal and unimodal agile IT organization. However, as companies of this type still divide their systems into internal backend and customer-centric systems, they struggle with some of the issues encountered by companies engaged in bimodal IT.

\section{Conclusion, Limitations and Outlook}

Although bimodal IT is perceived as an inevitable step towards digital business transformation, research on its implementation and its effects on alignment mechanisms remain, thus far, scarce. We have addressed these concerns by examining and structuring the practice-driven concept of bimodal IT and its relation to bimodal (business) IT alignment. We confirmed that several implementation approaches, ranging from bimodal development to a transformation towards agility of the whole IT organization, exist in practice. We also found that bimodal IT still mainly implies the transformation of 
the IT organization and does not focus on transforming the whole organization; this continues to separate business from IT.

Our study is mainly limited by its small sample size. Further, the data of our empirical study are restricted to service-related industries in a single country. Therefore, generalizing our results is possible to only a limited extent. We approached this limitation by choosing organizations of different sizes and from different industries. Further, we were careful to choose only interview partners who were experienced in bimodal IT. Still, our results require further input from different industries and regions.

Future research might address the question of how alignment is enabled within the IT function and in relation to business. Thus, research on best practices and contingency factors that foster or hinder alignment is necessary. Finally, further inquiries into the contingency factors influencing the different bimodal organizational designs must be conducted.

\section{References}

[1] Gartner, IT Glossary: Bimodal IT, 2015.

[2] Bossert, O., J. Laartz, J., and T.J. Rams $\varnothing y$ Running your company at two speeds, 2014.

[3] Gourévitch, A., B. Rehberg, and J.F. Bobier, TwoSpeed IT: A Linchpin for Success in a Digitized World, 2012.

[4] Chen, L., "Business-IT alignment maturity of companies in China", Information \& Management, 47(1), 2010, pp.9-16.

[5] Luftman, J. and T. Ben-Zvi, "Key issues for IT executives 2010: Judicious IT investments continue postrecession", MIS Quarterly Executive, 9(4), 2010, pp.263273.

[6] Bygstad, B., "The Coming of Lightweight IT", Proceedings of the 23rd European Conference on Information Systems, 2015, pp.1-16.

[7] Horlach, B., P. Drews, and I. Schirmer, "Bimodal IT: Business-IT Alignment in the Age of Digital

Transformation", Proceedings on the Multikonferenz Wirtschaftsinformatik, 2016, pp.1417-1428.

[8] Chan, Y.E. and B.H. Reich, "IT alignment: what have we learned?", Journal of Information Technology, 22(4), 2007, pp.297-315.

[9] Ullah, A. and R. Lai, "A Systematic Review of Business and Information Technology Alignment", ACM Transactions on Management Information Systems, 4(1), Article 4, 2013, pp.1-30.

[10] Henderson, J.C. and H. Venkatraman, "Strategic alignment: Leveraging information technology for transforming organizations", IBM Systems Journal, 32(1), 1993, pp.472-484.

[11] Coltman, T., P. Tallon, R. Sharma, and M. Queiroz, "Strategic IT Alignment: Twenty-Five Years On", Journal of Information Technology, 30(2), 2015, pp.91-100.
[12] Salim, J. and E.A.A. Seman, "Antecedents factors affecting alignment and its impact to organizational performance in universities", Proceedings of the International Conference on Business Administration, Marketing and Economics, 2013, pp.106-112.

[13] Onita, C. and J. Dhaliwal, "Alignment within the corporate IT unit: an analysis of software testing and development", European Journal of Information Systems, 20(1), 2011, pp.48-68.

[14] Tan, F.B. and R.B. Gallupe, "Aligning business and information systems thinking: A cognitive approach", IEEE Transactions on Engineering Management, 53(2), 2006, pp.223-237.

[15] Reich, B. and I. Benbasat, "Factors That Influence the Social Dimensions of Alignment Between Business and Information Technology Objectives", MIS Quarterly, 24(1), 2000, pp.81-113.

[16] Jenkin, T.A. and Y.E. Chan, "IS project alignment - a process perspective", Journal of Information Technology, 25(1), 2009, pp.35-55.

[17] Wagner, W. and T. Weitzel, "How to Achieve Operational Business-IT Alignment - Insights from a Global Aerospace Firm", MIS Quarterly Executive, 11(1), 2012, pp.25-36.

[18] QualiSystems Ltd., Bimodal IT, 2015.

[19] Cuomo, J., L. Yusuf, A. Gibbs, and S. Cerverny, The Era of the Now: Embracing Two Speed Integration by IBM, 2015.

[20] Bils, S., Two-speed IT: Necessary, But Not Sufficient, 2014.

[21] Bharadwaj, A., O.A. El Sawy, P.A. Pavlou, and N. Venkatraman, "Digital business strategy: toward a next generation of insights", MIS Quarterly, 37(2), 2013, pp.471-482.

[22] Matt, C., T. Hess, and A. Benlian, "Digital Transformation Strategies", Business \& Information Systems Engineering, 57(5), 2015, pp.339-343.

[23] Krogh, G., C. Rossi-Lamastra, and S. Haefliger, "Phenomenon-based Research in Management and Organisation Science: When is it Rigorous and Does it Matter?", Long Range Planning, 45(4), 2012, pp.277-298. [24] Biernacki, P. and D. Waldorf, "Snowball Sampling: Problems and Techniques of Chain Referral Sampling", Sociological Methods \& Research, 10(2), 1981, pp.141163.

[25] Myers, M.D. and M. Newman, "The qualitative interview in IS research: Examining the craft", Information and Organization, 17(1), 2007, pp.2-26.

[26] Miles, M.B., A.M. Huberman, and J. Saldaña, Qualitative data analysis: A methods sourcebook, SAGE Publications, Inc, Thousand Oaks, California, 2014. [27] Corbin, J.M. and A.L. Strauss, Basics of qualitative research: Techniques and procedures for developing grounded theory, SAGE, Los Angeles, 2015.

[28] Leffingwell, D., D. Jemilo, R. Knaster, I. Oren, and A. Yakyma, Scaled Agile Framework (SAFe), 2016. [29] Yarow, J., This Is The Internal Grading System Google Uses For Its Employees - And You Should Use It Too, 2014.

[30] Kniberg, H. and A. Ivarsson, Scaling Agile @ Spotify with Tribes, Squads, Chapters \& Guilds, 2012. 